\title{
A DEMOCRACIA E O NOSSO SANGUE: PARÁFRASE DISCURSIVA E COMPREENSÃO DAS REFERÊNCIAS
}

Rodrigo Oliveira Fonseca ${ }^{\mathrm{a}}$

\begin{abstract}
RESUMO
O presente artigo explora o recurso da paráfrase discursiva (HENRY, 1990) para compreender a referencialidade de democracia em intervençóes recentes do presidente Jair Bolsonaro, e sua relação com o que é dito acerca da defesa das cores verde e amarela na Bandeira Nacional.

PALAVRAS-CHAVE: Paráfrase; Democracia; Inimigo Interno.
\end{abstract}

Recebido em: 16/06/19

Aprovado em: 18/09/19

\section{Democracia se as forças armadas quiserem}

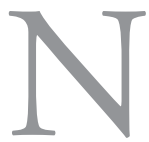

o início de março de 2019, em cerimônia de aniversário do Corpo de Fuzileiros Navais, uma fala do presidente Jair Bolsonaro chamou a atenção e virou notícia: democracia e liberdade só existiriam com a anuência das Forças Armadas de um país. Após afirmar que havia recebido a vitória nas eleiçôes presidenciais como uma missão - termo central no jargão militar -, o presidente disse que essa missão seria cumprida.

[...] ao lado das pessoas de bem do nosso país, daqueles que amam a pátria, daqueles que respeitam a família, daqueles que querem aproximação com países que têm ideologia semelhante

a Universidade Federal do Sul da Bahia, Doutor em Estudos de Linguagem pela UFRS. 
à nossa, daqueles que amam a democracia. $\mathrm{E}$ isso, democracia $\mathrm{e}$ liberdade, só existe quando a sua respectiva Força Armada assim o quer (DELGADO, 2019).

Dada a enorme e negativa repercussão, algumas autoridades do governo saíram em defesa do presidente, acusando problemas na interpretação do seu discurso: "está sendo mal interpretado. O presidente falou que onde as Forças Armadas não estão comprometidas com democracia e liberdade esses valores morrem. É o que acontece na Venezuela”, disse o vice-presidente general Hamilton Mourão (BRANDÃO, 2019; FERNANDES, 2019); "ele falou o que todo mundo sabe: as Forças Armadas são o baluarte da democracia e da liberdade. Historicamente, em todos os países do mundo", defendeu o ministro-chefe do Gabinete de Segurança Institucional, general Augusto Heleno (FERNANDES, 2019).

Em defesa da clareza e do acerto da fala do presidente, os dois generais apresentaram interpretaçóes divergentes. Ainda que estas tenham operado a diluição do caráter arbitrário evocado na fala do presidente, fizeram-no de modo discrepante. Mourão transformou o QUANDO da fala original (democracia e liberdade só existe quando a sua Força Armada assim o quer) em ONDE, apresentando o problema da falta de vontade/ compromisso com a democracia por parte das Forças Armadas em um problema histórico ou geopolítico: há países em que as Forças Armadas não estão comprometidas com a democracia - problema que não ocorreria no Brasil, mas talvez em uns poucos países como a Venezuela. Em síntese, não haveria democracia e liberdade onde (nos países em que) as Forças Armadas não são democráticas.

Heleno foi além e, naturalizando e universalizando a relação entre democracia e Forças Armadas (baluarte, base, alicerce da democracia), arriscou transformar a frase do presidente em non sens, afinal, SE existem democracia e liberdade É PORQUE existem Forças Armadas, pois, do contrário, não haveria democracia e liberdade. Tratar-se-ia, assim, nem de arbítrio dos militares, nem de razões ligadas à formação histórica e geopolítica do país, mas de uma questão puramente lógica e institucional. As Forças Armadas seriam, basicamente, uma condição da existência de regimes democráticos. 
No entanto, poucas semanas depois, no final do mês de março, em entrevista à Rede Bandeirantes de Televisão, o presidente retomou, de modo ainda mais didático, seu posicionamento acerca da relação entre as Forças Armadas e a democracia: "Em qualquer país do mundo, em última análise, quem decide se vai ser democracia ou ditadura são as Forças Armadas. Não vai ser a Ordem dos Advogados do Brasil, não vai ser o Conselho Federal de Medicina, não vai ser a Confederação Nacional da Indústria” (VEJA, 2019).

Ao contrário das substituiçóes operadas pelo ONDE de Mourão e pelo PORQUE de Heleno, o QUEM de Bolsonaro restituiu a força da arbitrariedade.

\section{Bandeira vermelha para mantê-la verde e amarela}

No dia primeiro de janeiro de 2019, ao final do seu discurso de posse no parlatório do Palácio do Planalto, já com a faixa presidencial e dirigindo-se aos apoiadores concentrados no gramado, Bolsonaro recebeu uma Bandeira do Brasil das mãos do futuro ministro da Casa Civil, Onyx Lorenzoni, que gesticulou ao presidente em sinal para que balançasse a bandeira. Então, em um momento único de fala espontânea (já havia terminado a leitura do texto previamente preparado), e, segurando a Bandeira Nacional junto com o vice-presidente Hamilton Mourão, Bolsonaro disse o seguinte:

Essa é a nossa bandeira que jamais será vermelha. [sorri, levanta o polegar e faz uma pausa de quatro segundos] Só será vermelha se for preciso [olha para o general Mourão e retorna para o público] o nosso sangue pra mantê-la verde e amarela (SOUZA, 2019).

Temos aí uma espécie de pacto de morte em torno da manutenção "das cores da bandeira" - nossa bandeira só será vermelha se for preciso o nosso sangue pra mantê-la verde e amarela. Ou seja, jamais haverá socialismo no país, o pior que pode acontecer é a bandeira ficar vermelha com o sangue derramado em sacrifício para que ela permaneça verde e amarela.

Pelo movimento corporal do orador, NOSSO (em nosso sangue) parece referir-se à chapa eleita, mas, no entanto, sendo esta formada por dois militares da reserva, podemos pensar também numa referência ampliada para as 
Forças Armadas, agora sob o comando de Jair Bolsonaro, que nomeou oito militares em seu gabinete - uma proporção maior de ministros militares do que a existente nos governos de 1964 a 1985, descontadas as pastas militares. E tomando o contexto imediato, o encontro do líder com os seus apoiadores, a referência de NOSSO (sangue) pode ainda encontrar outro objeto, o campo político que venceu as eleiçôes no segundo turno. Essa segunda alternativa é verossímil e encontra eco na repercussão dada pela imprensa ao discurso de posse do presidente no parlatório, uma fala considerada ainda totalmente eleitoral.

A circulação desse enunciado foi bem menor em comparação com o enunciado ocorrido tempos depois, no mês de março, sobre as Forças Armadas e a democracia, que comentamos antes. Mas os seus movimentos de reescrita e relato social são interessantes, posto que apontam para as derivas da interpretação. $\mathrm{O}$ portal Terra publicou, no mesmo dia, como manchete "Nossa bandeira só será vermelha se for preciso sangue para mantê-la verde e amarela, diz Bolsonaro" (PARAGUASSU, 2019a). Somente no corpo do texto a jornalista Lisandra Paraguassu restitui o NOSSO do enunciado proferido. Já no jornal Valor, em matéria com a manchete “Nossa bandeira jamais será vermelha', afirma Bolsonaro na posse” (FERNANDES; ARAÚJO; AGOSTINE; FILGUEIRAS, 2019), a passagem em questão aparece da seguinte forma no corpo do texto: "Ao falar no parlatório, durante solenidade no Palácio do Planalto, Bolsonaro manteve o tom de ataque das eleiçóes, ao dizer que a bandeira do país 'jamais será vermelha', mesmo que seja preciso 'o nosso sangue para mantê-la verde e amarela”. Em matéria da Reuters, publicada também no portal UOL e assinada pela mesma jornalista da matéria do portal Terra, a manchete foi a seguinte: "Bandeira só será vermelha se for preciso sangue para mantê-la verde e amarela, diz Bolsonaro" (PARAGUASSU, 2019b). E no corpo do texto "segurando uma bandeira do Brasil, [Bolsonaro] disse que ela só será vermelha se for preciso o sangue para mantê-la verde e amarela”.

Essa entrada e saída dos possessivos NOSSA e NOSSO para bandeira e para sangue joga com uma característica forte da discursividade política, a indeterminação referencial, pela designação - mediante toda a série referida à primeira pessoa do plural (nós, nos, nosso e desinência verbal de primeira pessoa do plural) - de conjuntos lexicalmente não nomeados (GUESPIN, 
1985 apud INDURSKY, 1997, p. 66). Afinal, qual sangue está sendo indicado como cauçấo no contrato de Bolsonaro com seus apoiadores? E, afinal, qual será mesmo o produto do acordo? O que significa - em especial para a democracia - "manter a bandeira verde e amarela"?

\section{Países com ideologia semelhante?}

Para avançarmos numa reflexão acerca das discursividades do atual governo brasileiro em torno dos sentidos de democracia, passaremos pela temática fregeana da referência e do sentido conforme as abordagens de Michel Pêcheux (1997 [1975]), Eduardo Guimarães (1995) e Bethania Mariani (1998), chegando a questóes propostas por Paul Henry (1990 [1975]) acerca da paráfrase discursiva e da referencialidade. Vejamos três sentenças que apontam para um mesmo conjunto de objetos, ou seja, possuem os mesmos referentes, constituindo assim paráfrases pertinentes:

1. O presidente governará com aqueles que querem aproximação com países que têm ideologia semelhante à nossa;

2. O presidente governará com aqueles que querem aproximação com países que têm ideologia semelhante à dele;

3. O presidente governará com aqueles que querem aproximação com países como os Estados Unidos de Trump, Israel de Netanyahu, a Itália de Salvini, o Chile de Piñera, a Hungria de Orban e a Polônia de Duda ${ }^{1}$.

Para alguém que conheça a agenda política do presidente desde as eleiçôes de 2018, a referência ao final das três sentenças parece ser exatamente a mesma, havendo, pois, identidade referencial na designação desse grupo de

1 Os quatro primeiros países foram citados por Bolsonaro em novembro de 2018 como naçóes com as quais ele tinha mais afinidade; quanto à Hungria e à Polônia, são países com governos irmanados por Steve Bannon, ex-assessor de Trump, em torno de uma internacional de extrema-direita (The Movement), que passou a incluir também o governo de Bolsonaro. Em maio, o presidente brasileiro anunciou o desejo de visitar os dois países no segundo semestre de 2019. Cf. IG SÃO PAULO (2019). 
países. É como se a sequência (1), efetivamente realizada, existisse enquanto um desdobramento de "já ditos" e ditos de outros modos - que poderiam ser (2) ou (3). Porém, essas diferentes formas de apresentação de uma designação conduzem a sentidos não só diferentes como controversos entre si, desconstruindo - pelo viés do exercício parafrástico demonstrado há pouco - o projeto enunciativo contido em nossa (ideologia), que, ao invés de uma associação intradiscursiva com nosso país ("as pessoas de bem do nosso país"), passa a funcionar semanticamente de modo restrito, a ideologia do nossolmeu governo, a minha ideologia, que seria semelhante à ideologia de outros países.

Existe uma dificuldade em torno da associação metonímica entre países e ideologias ${ }^{2}$, e também em torno dessa associação entre governos (extraídos dessa relação países/ideologias) que, supostamente, representariam as ideologias de seus respectivos países e ainda conformariam um "campo semelhante". $\mathrm{Ou}$ seja, para se poder sustentar que nossa ideologia é um modo de apresentação de "a ideologia dos brasileiros", deveríamos igualmente supor que essa ideologia é semelhante à "ideologia dos estadunidenses", à "ideologia dos italianos", à "ideologia dos húngaros" etc. Se a referência comum fica esgarçada perante os diferentes sentidos, do menos (1) ao mais (3) restrito, ou do menos ao mais determinado, o que confirma a tese de Gottlob Frege (PÊCHEUX, 1997 [1975]) quanto à existência de expressóes dotadas de sentido mas sem referência objetiva no mundo das coisas, como "banho de sangue". No entanto, também é verdade que para o "mundo das coisas" as referências não são unívocas a ponto de se poder estabelecer uma única designação. Por isso mesmo, os sentidos, que não são objetos do mundo, constituem as formas fundamentais de se conhecerem as referências (GUIMARÁES, 1995, p. 27), que não nos chegam senão por meio de apresentaçôes, de "olhares", isto é, já encharcadas de sentidos, já tomados de história e apreendidos em meio a ela.

Mostraremos, um pouco mais adiante, a dificuldade de determinação em torno de nossa democracia, tal como essa construção se apresentou no processo de cassação do registro do Partido Comunista do Brasil (PCB) em 1947, mas queremos, antes disso, investigar outro aspecto da mesma formulação

2 Qual seria, por exemplo, a referência para ideologia alemã? Aquela analisada no livro de Marx e Engels? O nazismo? O governo de Angela Merkel e seu papel na União Europeia? 
presidencial sobre países e ideologias. Fazendo o teste básico de identificação daquilo que é pressuposto na sentença de Bolsonaro - pela negativa, "O presidente não governará com aqueles que querem a aproximação com X”, e pela interrogativa, "O presidente governará com aqueles que querem a aproximação com X?” -, vemos que elemento não é objeto de refutação ou dúvida no conjunto do pensamento desenvolvido na sentença: existem aqueles que querem a aproximação com um (in)determinado grupo de países. A afirmação incide sobre esse grupo de pessoas que, no fio do discurso, são pessoas de bem, que amam a pátria e a democracia e respeitam a família. Uma interpretação contrastiva, bastante corriqueira no campo da política, conduz à evocação semântica do contraponto entre essas pessoas/aqueles e outras pessoas/aqueles outros, que não respeitam a família, não amam a pátria e a democracia, e, por conseguinte, não querem a aproximação com esse (in)determinado grupo de países. Também pelo fio do discurso, podemos inferir que essas outras pessoas (derrotadas nas eleiçóes?) não admitem que as Forças Armadas sejam as maiores fiadoras das democracias (ou das ditaduras), quando assim o querem. E, desse modo, passamos da identificação de um pressuposto da sentença - a existência de um (in)determinado grupo de pessoas que quer a aproximação com um (in)determinado grupo de países - ao início da compreensão de um pré-construído, a inserção e a leitura da formulação do presidente Bolsonaro no interior de uma determinada organização de referências políticas e discursivas já instituídas alhures. Mas onde? Nas coordenadas instituídas em meio à Guerra Fria?

\section{Países e regimes com tradição democrática comum?}

Os comunistas ocupam, com destaque, o lugar de inimigos internos no imaginário político dominante brasileiro desde a década de 1930 (MARIANI, 1998; MOTTA, 2002; RODEGHERO, 2003). Um lugar antes ocupado com folga pelos indígenas, depois pelos africanos e, até a década de 1920, pelos anarquistas, A Guerra Fria potencializou enormemente a propaganda anticomunista. E não somente a propaganda. Em 1949 foi fundada no Brasil a ESG, Escola Superior de Guerra, braço de cooperação técnica e ideológica dos militares anticomunistas com os seus pares dos Estados Unidos, que, em 
1947, haviam criado a Comissão Nacional de Segurança e a mais famosa das agências de investigação política, a CIA (Agência Central de Inteligência, na tradução da sigla em inglês). Neste período, leis e agências estatais anticomunistas também foram criadas na Inglaterra, Chile, Portugal, Bolívia, Austrália, África do Sul e Canadá (REZNIK, 2004, p. 20). Formando militares e civis, empresários e políticos, em 1952, a ESG, sob a direção do general Golbery do Couto Silva, estabeleceu três objetivos de longo prazo para a instituição: projeção em direção ao Pacífico; controle da Amazônia; e aliança com os EUA contra o comunismo (ZIBECHI, 2019).

Os votos dos juízes que decidiram pela cassação do registro do Partido Comunista Brasileiro (PCB), há setenta e dois anos, apresentam-nos questóes de linguagem interessantes para a reflexão presente no campo do discurso ${ }^{3}$. Em vários momentos, uma (in)determinada tradição democrática brasileira é esboçada, insinuada, como vindo desde o Império, tramada em identidade com certa cultura democrática dos Estados Unidos:

(4) a Democracia de Roosevelt, aquela que vem de Lincoln, aquela que recebemos dos nossos antepassados, aquela que o Brasil Império nos legou, aquela que o Brasil República consolidou, aquela que hoje cumpre defender e aplicar, aquela que justificou a carnificina da última guerra e que ainda cobre de luto várias famílias patrícias, enfim, aquela Democracia como nós entendemos que o seja, aquela que Rui Barbosa definiu e pregou conforme estavam consubstanciadas nas diversas Constituições (FONSECA, 2016, p. 215)

(5) a Democracia, aquela que é estabelecida como norma pela Constituição Brasileira, aquela que é do Brasil e dos brasileiros, aquela que vem dos nossos antepassados e que deles com honra e orgulho herdamos para transmitir aos nossos sucessores,... (FONSECA, 2016, p. 216).

3 Retomo a partir daqui algumas das análises desenvolvidas em Fonseca (2016), produzindo novas abordagens e consideraçóes. 
Como destacado em Fonseca (2016), existe um trabalho reiterado de um determinante linguístico - com os itens lexicais "aquela que" -, visando à restrição da referência de democracia, sendo esta aquela que $\mathrm{X}$, não uma democracia qualquer, e não exatamente "esta", que, sem os complementos, poderia extravasar para a democracia tal como defendida pelos comunistas, que, há pouco tempo, haviam tido um papel de destaque na luta internacional contra o nazi-fascismo e mesmo na "carnificina da última guerra".

A determinação, em tese, não altera nem acrescenta significação ao termo determinado, apenas delimita a significação, oferecendo - pela via de um determinante acrescido (a democracia; democracia brasileira; democracia que sonhamos; sua democracia) - uma possibilidade de referência para o sujeito, preenchendo assim uma função de designação. No entanto, o pronome demonstrativo ("aquela"), na função de determinante, pela enorme diversidade de apresentaçóes/sentidos propostos, menos demonstra e designa do que "engarrafa” e opacifica a referência ${ }^{4}$. É sobretudo a injunção à interpretação que propicia o efeito de que "se sabe exatamente sobre isso que se está falando". Em vez de, no fio do discurso, conduzir retomadas que iriam do menos ao mais restrito e determinado, como em (1)-(3), a reiteração do pronome demonstrativo, com distintos complementos em (4) e (5), co(i)mplica a referenciação, parecendo sussurrar nas lacunas outros textos do domínio de memória naquela conjuntura dos dizeres: "a Democracia do Brasil e dos brasileiros não é a democracia deles, dos comunistas, que (por demagogia) não falam de outra coisa”.

Se os sentidos, formas de apresentação e construção verbal das referências, são os meios de conhecê-las, é curioso que, sob a ocorrência reiterada de um demonstrativo, o funcionamento maior seja a reserva de um espaço outro e negativo não para essa referência, a Democracia do Brasil e dos brasileiros (que não se deixa circunscrever facilmente), mas sim para qualquer outra democracia que viesse a ser evocada no processo de cassação. E aquilo que deveria

4 Para pensar esse efeito, podemos tomar uma charge da Laerte (em GALLEGO, 2018) na qual uma oradora - sobre um palco em um comício a favor de Bolsonaro - diz "Precisamos evitar o pensamento único". Entáo, uma pessoa no meio da massa grita, perguntando “Como assim 'pensamento'?". A questão, para aproveitarmos bem a charge, não seria tanto o desconhecimento lexical do termo determinado, mas também e sobretudo os problemas que o determinante acrescido ocasionam à construção da referência, em vez de melhorá-la. 
estar em questão no julgamento, a “democracia deles", dos comunistas, nem é referida, não aparece nos votos o programa de União Nacional defendido desde 1943 pelo $\mathrm{PCB}$, as dezenas de propostas apresentadas à Constituinte pelo seu senador e seus catorze deputados, e nada que aponte para a plataforma eleitoral do PCB, respaldada por $10 \%$ do eleitorado brasileiro 5 .

\section{O que seria do verde e amarelo sem o vermelho?}

Pelas formulaçóes dos votos dos juízes, ficamos sem saber como é essa democracia do Brasil e dos brasileiros. Trabalha-se uma lista de possibilidades de sentidos, mas absolutamente nenhuma referência estável para além do fato de interditar a democracia como um valor e um programa que pudesse ser compartilhado por/pelos comunistas. Possibilidades que funcionam no discurso de cassação como a contraparte negativa que sustenta uma afirmação, "o Outro necessário à reafirmação da positividade do campo do mesmo" (MARIANI, 1998, p. 96), ainda quando essa afirmação pareça apontar para uma estrutura consideravelmente vazia ou impressionista. É por isso que "manter a bandeira verde e amarela" é tão difícil de ser parafraseado fora do confronto (em geral imaginário e estratégico) com os vermelhos, e é também por isso que uma polarização política extrema não costuma representar o verdadeiro confronto entre práticas discursivas e ideológicas, e sim um "antagonismo oficial” (ŽIŽEK, 2012), estrategicamente sustentado, que foraclui aquilo que

5 Na eleição de 1945, o único candidato à presidência da República que não era militar era o candidato lançado pelo PCB, o ex-prefeito de Petrópolis Yedo Fiúza, um desconhecido no cenário nacional que nem mesmo era comunista (o que fazia parte da política de União Nacional), mas que conseguiu $10 \%$ dos votos graças ao prestígio dos comunistas a partir da derrota do nazi-fascismo. Além de eleger Prestes para o Senado, o PCB elegeu para a Câmara Federal Jorge Amado, Carlos Marighella, e quadros políticos operários como Abílio Fernandes (metalúrgico), Alcides Sabença (da construção civil e carpinteiro), Claudino José da Silva (único parlamentar negro da Constituinte de 1946, ferroviário), Agostinho Dias Ferreira (também ferroviário) e Osvaldo Pacheco da Silva (estivador), num total de 14 deputados. No início de 1947, ano da cassação do PCB, houve eleição nos estados e municípios, tendo o PCB feito 46 deputados nos 15 estados existentes à época, e cerca de 250 vereadores em todo o país, formando as maiores bancadas das Câmaras Municipais do Rio de Janeiro (ainda Distrito Federal) e também de São Paulo, Santos e Recife. Esse era o partido que estava sendo cassado sob a acusaçáo de não ser brasileiro. 
lhe é insuportável e que representa de fato o campo contra o qual e no qual este se (in) dispóe ${ }^{6}$.

O que parece uma obsessão e um despropósito é, na verdade, fundamental para a afirmação ideológica de uma força política, sendo que uma tal afirmação se dá muito mais na tematização do outro do que na de si. Karl Marx, n'O 18 Brumário de Luis Bonaparte, abordou o caráter, ao mesmo tempo, monossilábico e enigmático do partido da ordem, tanto na tribuna da Assembleia Nacional francesa quanto na sua imprensa:

[...] fastidiosos como um enigma cuja solução é de antemão conhecida. Quer se trate do direito de petiçáo ou do imposto sobre as bebidas, da liberdade de imprensa ou da liberdade de troca, de clubes ou organização municipal, da protecção à liberdade pessoal ou da regulamentação do orçamento, a palavra de ordem mantém-se sempre a mesma, o tema é constante, a sentença está sempre pronta e é invariavelmente a mesma: Socialismo! É socialista o próprio liberalismo burguês, a cultura burguesa, a reforma financeira burguesa. Era socialismo construir um caminho de ferro onde já havia um canal, e era socialismo defender-se com um cacete quando se era atacado com uma espada (MARX, 1975 [1852], p. 72, grifo do original).

Mas por que, então, a apresentação na forma de "enigma", ainda que fácil? A resposta pode vir na forma de outra pergunta: por que interpretamos tão facilmente sentenças que tão dificilmente fariam sentido se sua referencialidade estivesse totalmente presa a substituiçóes/paráfrases autorizadas apenas pelo fio do discurso? Dito de outra forma: como interpretaríamos com facilidade enigmas que seriam insolúveis se contássemos apenas com as suas pistas internas, sem a sustentação em uma memória? No caso de piadas em forma de charadas, existem aquelas que, às vezes, conseguimos responder apenas jogan-

6 Não fosse isso também, não haveria casos anedóticos como o do general Coelho Netto, quando, no dia seguinte ao jogo Brasil 2x1 União Soviética pela Copa do Mundo de 1982, em uma coletiva de imprensa, surpreendeu os jornalistas dizendo "Ganhamos de vocês ontem!" (CONTREIRAS, 1998, p. 56). 
do com uma polissemia própria do seu campo temático, sem que tenhamos conhecimento prévio da charada em si, como no caso de "Por que o livro de matemática é depressivo? / Porque tem muitos problemas”. O mesmo não acontece com charadas que parecem jogar com o aleatório, às quais só conseguimos responder se temos conhecimento prévio da convenção que sustenta o seu efeito cômico, ou se já a escutamos antes, como no caso de "O que é um pontinho metálico na grama? / Uma formiga de aparelho", ou "O que é um pontinho branco correndo no meio da mata? / Uma formiga vestida de noiva atrasada para o casamento".

Que todos os sinais de uma discursividade possam ser substituídos/parafraseados por formigas ou por socialismo, esse é um mecanismo próprio dos pré-construídos, pelo qual uma determinada e recorrente substituibilidade constitui o objeto do discurso em objeto exterior a uma textualização, "precisamente porque ele [o objeto do discurso] é susceptível de aí figurar por formas diferentes daquela que o representa, sem que o sentido do discurso seja modificado" (HENRY, 1990 [1975], p. 52).

Para concluir, deixamos como hipótese tomar a indeterminação referencial de democracia no discurso do atual governo brasileiro como implicada nos pré-construídos em torno da enigmática (mas fácil de parafrasear discursivamente) "manutenção da bandeira verde e amarela", com uma clareza maior do que a do anticomunismo de 1947 e uma maior paleta de cores inimigas. Uma fala do ministro Onyx Lorenzoni parece ilustrar o sentido do esforço para a manutenção das cores originais da bandeira de um país: "No período de Pinochet, o Chile teve de dar um banho de sangue. Triste, o sangue lavou as ruas do Chile, mas as bases macroeconômicas fixadas naquele governo... já passaram oito governos de esquerda e nenhum mexeu nas bases macroeconômicas colocadas no Chile no governo Pinochet" (URIBE, 2019).

$\mathrm{E}$ assim banho de sangue, que dissemos antes não possuir referência objetiva no mundo das coisas, ganha outra estatura, é um (re)agente de limpeza social quando os países têm de reagir. Se "Pinochet" foi um período, qual será o nosso? Edson Teles (2018) responde: desde a promulgação da Constituição vigente, e com muito maior ênfase desde 2013, o Brasil vem passando por um processo de militarização da gestão social que demanda e potencializa a 
ideologia do inimigo interno. "A democracia manteve a concepção de segurança pública como a guerra contra o inimigo, este variando entre 'bandidos', militantes de movimentos sociais, jovens negros e pobres, loucos, traficantes, pessoas LGTBIs, indígenas” (TELES, 2018, p. 70). A opção militarista pela democracia, comprometida em "manter a bandeira verde e amarela", pode ser também a busca por uma ampliação da liberdade de ação do corpo social formado pelas pessoas de bem para poderem reagir a vermelhos cada vez mais coloridos e disfarçados.

\section{Referências}

BRANDÃO, Marcelo. Mourão: Bolsonaro foi mal interpretado em fala sobre as Forças Armadas. Agência Brasil, Brasília, 07 mar. 2019. Disponível em: <http://agenciabrasil.ebc.com.br/politica/noticia/2019-03/mourao-bolsonaro-foi-mal-interpretado-em-fala-sobre-forcas-armadas $>$. Acesso em: 13 nov. 2019.

CONTREIRAS, Hélio. Militares: confissões. Histórias secretas do Brasil. Rio de Janeiro: Mauad, 1998.

DELGADO, Malu. Cem dias do governo Bolsonaro. Valor, São Paulo, 10 abr. 2019. Disponível em: <https://www-preprod.valor.com.br/?q=especial/cem-dias-do-governo-bolsonaro>. Acesso em: 13 nov. 2019.

IG SÃO PAULO. Eduardo Bolsonaro encontra ministro italiano e se desculpa por asilo a Battisti. Disponível em: <https://ultimosegundo.ig.com.br/mundo/2019-04-19/eduardo-bolsonaro-encontr a- ministro-italiano-e-se-desculpa-por-asilo-a-battisti.html>. Acesso em: 13 mai. 2019.

FERNANDES, Maria Cristina; ARAÚJO, Carla; AGOSTINE, Cristiane; FILGUEIRAS, Malu. 'Nossa bandeira jamais será vermelha', afirma Bolsonaro na posse. Valor, São Paulo, 01 jan. 2019. Disponível em: https://valor.globo.com/politica/noticia/2019/01/01/nossa-bandeira-jamais-sera-vermelha-afirma-bolsonaro-na-posse.ghtml. Acesso em: 13 nov. 2019.

FERNANDES, Talita. Fala de Bolsonaro sobre militares e democracia foi mal interpretada, diz Mourão. Folha de São Paulo, São Paulo, 7 mar. 2019. Disponível em: https://www1.folha.uol.com.br/poder/2019/03/fala-de-bolsonaro-sobre-militares-e-democracia-foi-mal-interpretada-diz-mourao.shtml. Acesso em: 13 nov. 2019. 
FONSECA, Rodrigo Oliveira. A interdição discursiva na cassação do PCB em 1947. In: TFOUNI; STÜBE; PAULON (org.). Silêncio e Interdito: discursos em movimento. São Carlos, SP: Pedro \& João, 2016, p. 203-240. GALLEGO, Esther Solano (org.). O ódio como politica: a reinvenção da direita no Brasil. São Paulo: Boitempo, 2018.

GUIMARÁES, Eduardo. Os limites do sentido: um estudo histórico e enunciativo da linguagem. Campinas, SP: Pontes, 1995.

HENRY, Paul. Construções relativas e articulaçôes discursivas. Tradução de João Wanderley Geraldi e Celene Margarida Cruz. Caderno de Estudos Linguisticos, 19: 43-64, Campinas, SP, 1990 [1975].

INDURSKY, Freda. As falas dos quartéis e as outras vozes. Campinas, SP: Unicamp, 1997.

MARIANI, Bethania. O PCB e a imprensa: os comunistas no imaginário dos jornais (1922-1989). Rio de Janeiro: Revan; Campinas, SP: Unicamp, 1998.

MARX, Karl. O 18 ${ }^{\circ}$ Brumário de Luis Bonaparte. Lisboa: Vento do Leste, 1975 [1852].

MOTTA, Rodrigo Patto Sá. Em guarda contra o "perigo vermelho": o anticomunismo no Brasil (1917-1964). São Paulo: Perspectiva; Fapesp, 2002.

PARAGUASSU, Lisandra. Nossa bandeira só será vermelha se for preciso sangue para mantê-la verde e amarela, diz Bolsonaro. Terra, São Paulo, 01 jan. 2019a. Disponível em: https://www.terra.com.br/noticias/brasil/nossa-bandeira-so-sera-vermelha-se-for-preciso-sangue-para-mante-la-verde-e-amarela-diz-bolsonaro,c068079f48cdc1f3b000076c64b8f134ta08z4mo.html. Acesso em: 13 nov. 2019.

. Bandeira só será vermelha se for preciso sangue para mantê-la verde e amarela, diz Bolsonaro. Reuters, São Paulo, 01 jan. 2019b. Disponível em: https://economia.uol.com.br/noticias/reuters/2019/01/01/bandeira-so-sera-vermelha-se-for-preciso-sangue-para-mante-la-verde-e-amarela-diz-bolsonaro.htm. Acesso em: 13 nov. 2019.

PÊCHEUX, Michel. Semântica e Discurso: uma crítica à afirmação do óbvio. Tradução de Eni Orlandi [et. al.]. Campinas, SP: Unicamp, 1997 [1975].

RODEGHERO, Carla Simone. O diabo é vermelho: imaginário anticomunista e Igreja Católica no Rio Grande do Sul. (1945-1967). 2a edição. Passo Fundo, RS: UPF, 2003. 
REZNIK, Luís. Democracia e Segurança Nacional: a polícia política no pós-guerra. Rio de Janeiro: FGV, 2004.

SOUZA, Josias de. Na posse, Bolsonaro fala em pacto e conciliação. UOL, São Paulo, 01 jan. 2019. Disponível em: <https://josiasdesouza.blogosfera. uol.com.br/2019/01/01/na-posse-bolsonaro-fala-em-pacto-e-conciliacao/>. Acesso em: 13 nov. 2019.

TELES, Edson. A produção do inimigo e a insistência do Brasil violento e de exceção. In: GALLEGO (org.). O ódio como politica: a reinvenção da direita no Brasil. São Paulo: Boitempo, 2018, p. 65-72.

URIBE, Gustavo. Onyx elogia reformas da ditadura Pinochet e pondera revolução sangrenta. Folha de São Paulo, São Paulo, 21 mar. 2019. Disponível em: <> https:// www1.folha.uol.com.br/mercado/2019/03/onyx-elogia-reformas-da-ditadura-pinochet-e-pondera-revolucao-sangrenta.shtml. Acesso em: 28 mar. 2019.

VEJA, "O que eu tenho feito de errado?", pergunta Bolsonaro em TV, 27 mar. 2019. Disponível em <https://veja.abril.com.br/politica/o-que-eu-tenho-feito-de-errado-pergunta-bolsonaro-em-tv/>. Acesso em: 13 nov. 2019

ZIBECHI, Raul. O que querem os militares brasileiros? Le Monde Diplomatique Brasil, p. 16-17, fevereiro de 2019.

ŽIŽEK, Slavoj. Vivendo no fim dos tempos. Tradução de Maria Beatriz de Medina. São Paulo: Boitempo, 2012.

\title{
DEMOCRACY AND OUR BLOOD: DISCOURSE PARAPHRASE AND THE COMPREHENSION OF REFERENCES
}

\begin{abstract}
This article explores the use of discursive paraphrase (HENRY, 1990 [1975]) to understand the referentiality of democracy in recent interventions by President Jair Bolsonaro, and its relation to what is said about the defense of green and yellow colors in National flag.
\end{abstract}

KEYWORDS: Paraphrase; Democracy; Internal Enemy. 
